Connection between hydrogen plasma treatment and etching of amorphous phase in the layer-by-layer technique with very high frequency plasma excitation

O. Vetterl, P. Hapke, L. Houben, F. Finger, R. Carius, and H. Wagner

Citation: Journal of Applied Physics 85, 2991 (1999);

View online: https://doi.org/10.1063/1.369616

View Table of Contents: http://aip.scitation.org/toc/jap/85/5

Published by the American Institute of Physics

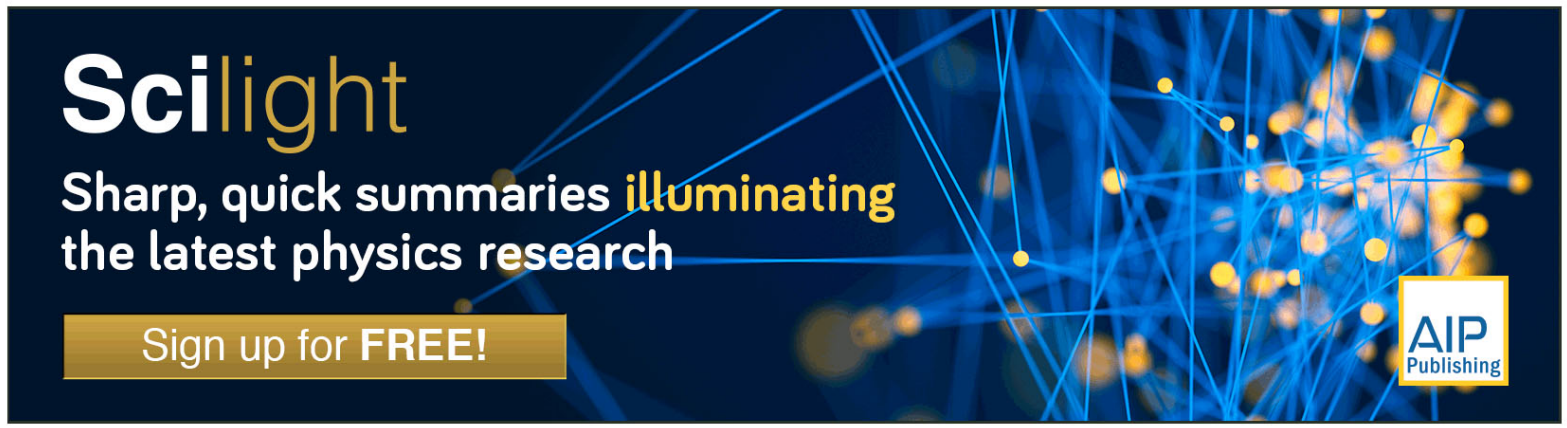




\title{
Connection between hydrogen plasma treatment and etching of amorphous phase in the layer-by-layer technique with very high frequency plasma excitation
}

\author{
O. Vetterl, ${ }^{\text {a) }}$ P. Hapke, L. Houben, F. Finger, R. Carius, and H. Wagner \\ Institut für Schicht-und Ionentechnik, Forschungszentrum Jülich, D-52425 Jülich, Germany
}

(Received 21 May 1998; accepted for publication 16 November 1998)

\begin{abstract}
The formation of microcrystalline silicon was investigated employing the layer-by-layer technique with very high frequency plasma excitation. Etching of the deposited layers was found to be a dominant effect during hydrogen plasma treatment. Microcrystalline growth occurred when the thickness of the deposited layer was reduced to a certain value in each cycle. The etching stopped when a noticeable crystalline volume fraction was produced; for long hydrogen treatment times no film growth was observed. (C) 1999 American Institute of Physics. [S0021-8979(99)06404-X]
\end{abstract}

The growth of microcrystalline silicon $(\mu c-\mathrm{Si}: \mathrm{H})$ is the subject of several present investigations. One controversial issue being discussed concerns the mechanism which causes microcrystalline formation in the layer-by-layer (LbL) process. ${ }^{1}$ In contrast to conventional plasma enhanced chemical vapor deposition (PECVD) techniques, where a continuous discharge of silane $\left(\mathrm{SiH}_{4}\right)$ highly diluted in hydrogen $\left(\mathrm{H}_{2}\right)$ is used for the deposition of $\mu c-\mathrm{Si}: \mathrm{H}$, the $\mathrm{LbL}$ process involves deposition under amorphous silicon $(a-\mathrm{Si}: \mathrm{H})$ growth conditions alternating with a hydrogen plasma treatment.

It was proposed that the hydrogen treatment transforms the $a$-Si:H into the crystalline phase within a certain growth zone below the film surface (chemical annealing). ${ }^{2,3}$ Alternative models include preferential etching of the amorphous phase $^{4,5}$ and enhanced mobility of film precursors on the surface due to hydrogen coverage. ${ }^{6,7}$ Recent results showed that chemical transport within the deposition system also has to be taken into account and that under conditions where this mechanism is excluded the hydrogen treatment of $a-\mathrm{Si}: \mathrm{H}$ causes only etching but no structural change. ${ }^{8}$ This could mean that the growth of $\mu c-\mathrm{Si}: \mathrm{H}$ in the LbL process is a surface phenomenon and not caused by a volume phase transformation. To further investigate this we applied plasma excitation frequencies $\nu_{\mathrm{ex}}$ from the very high frequency (VHF) range to the LbL technique.

Samples were prepared in a parallel plate PECVD system with a variable frequency VHF generator. All process parameters of the layer-by-layer deposition are summarized in Table I.

To alternate between the deposition and hydrogen treatment step we opened and closed the appropriate mass flow controllers using a computer algorithm. This allowed exact time control and resulted in samples of high reproducibility. As substrates, we used glass (Corning 7059) and glass covered with chromium. The chromium was used to cut out any contribution by the substrate in the Raman spectra. The thickness of the films was measured with a step profiler. To guarantee stable and reproducible conditions for the LbL ex-

${ }^{a)}$ Electronic mail: o.vetterl@fz-juelich.de periments, the deposition chamber was initially cleaned by glass blast and then covered with several $\mu \mathrm{m}$ of $a$-Si:H capping layers. Thus the cathode and the chamber wall (=plasma shield) are never etched clean during $\mathrm{H}$ plasma treatment. The chamber was kept under vacuum (base pressure $10^{-9}$ Torr) and sample loading was via a loadlock.

Figure 1 shows the total thickness of three series of LbL samples prepared at different plasma excitation frequencies with 15 cycles and the deposition time per cycle $t_{\text {dep }}$, held constant at $12 \mathrm{~s}\left(t_{\mathrm{H}}\right.$ series $)$.

The hydrogen treatment time $t_{\mathrm{H}}$ was varied in the range of 30-270 s. We observe a characteristic shape for all three curves with a linear decrease in thickness for $t_{\mathrm{H}}$ below a certain value $t_{C}$. For longer hydrogen treatment, the thickness shows a "plateau," i.e., it is independent of $t_{\mathrm{H}}$ over a certain range. For still longer $t_{\mathrm{H}}$ no film growth occurs. The plateau of constant thickness is less pronounced at lower plasma excitation frequencies, hardly able to be observed at $27 \mathrm{MHz}$, and most likely absent under rf (13.56 MHz) conditions. The vertical shift of the three curves indicates that the net growth rate (deposition minus etching) increases with $\nu_{\mathrm{ex}}$ as the deposition time $t_{\mathrm{dep}}=12 \mathrm{~s}$ was kept constant (which was the shortest time available to yield stable deposition conditions in our experimental setup).

Raman measurements show that the onset of the plateau of constant thickness at $t_{C}$ coincides with a structural change. This is shown for the $95 \mathrm{MHz}$ series in Fig. 2.

The films in the range $t_{\mathrm{H}}<t_{C}$ are clearly predominantly amorphous. As Raman spectroscopy has a detection limit for low crystalline volume fractions, ${ }^{9}$ the existence of small volumes with crystalline structure near the film surface, caused by chemical transport or phase transformation, cannot be excluded. However, prolonged $\mathrm{H}$ treatment (1800 s) of thick $a-\mathrm{Si}: \mathrm{H}$ (several $100 \mathrm{~nm}$ ) films always resulted in net etching and no observable structural change for any of the three $\nu_{\mathrm{ex}}$ conditions.

The decrease in thickness for $t_{\mathrm{H}}<t_{C}$ means that material is etched away. The corresponding etch rates can be computed from the slope of this approximately linear decrease as indicated in Fig. 1. These etch rates are identical to the etch 
TABLE I. Deposition parameters of layer-by-layer deposition.

\begin{tabular}{lcc}
\hline \multicolumn{1}{c}{ Parameter } & $t_{\mathrm{H}}$ series & $t_{\mathrm{dep}}$ series \\
\hline Substrate temperature, $T_{S}$ & $290{ }^{\circ} \mathrm{C}$ & $190{ }^{\circ} \mathrm{C}$ \\
Deposition total pressure, $p$ & $300 \mathrm{mTorr}$ & $300 \mathrm{mTorr}$ \\
Deposition time, $t_{\text {dep }}$ & $12 \mathrm{~s}$ & $15-40 \mathrm{~s}$ \\
Hydrogen treatment time, $t_{\mathrm{H}}$ & $30-270 \mathrm{~s}$ & $150 \mathrm{~s}$ \\
Number of cycles, $n$ & 15 & 15 \\
$\mathrm{Plasma} \mathrm{power,} P$ & $10 \mathrm{~W}$ & $10 \mathrm{~W}$ \\
$\mathrm{SiH}_{4} / \mathrm{H}_{2}$ flow during $t_{\mathrm{dep}}$ & $10 / 10 \mathrm{sccm}$ & $10 / 10 \mathrm{sccm}$ \\
$\mathrm{SiH}_{4} / \mathrm{H}_{2}$ flow during $t_{\mathrm{H}}$ & $0 / 100 \mathrm{sccm}$ & $0 / 100 \mathrm{sccm}$ \\
$\mathrm{Plasma} \mathrm{excitation} \mathrm{frequency} \nu_{\mathrm{ex}}$ & $27,50,95 \mathrm{MHz}$ & $50 \mathrm{MHz}$ \\
\hline \hline
\end{tabular}

rates of continuously grown $a-\mathrm{Si}: \mathrm{H}$ exposed to a prolonged hydrogen plasma. We suppose that at $t_{\mathrm{H}}<t_{C}$ the amorphous phase is deposited and etched alternately. If there would have been a transformation from the amorphous to the crystalline phase in the near surface region, a significant decrease of the etch rate would be expected. ${ }^{10}$ The lower etch rate for the crystalline phase compared to that of the amorphous phase can also explain why the film thickness at $t_{\mathrm{H}}>t_{C}$ is independent of $t_{\mathrm{H}}$ over a certain range. Crystalline regions are more stable under hydrogen treatment and therefore the increase of $t_{\mathrm{H}}$ no longer results in a measurable decrease of thickness. Figure 2 also shows an increase of crystalline volume fraction with $t_{\mathrm{H}}$ within the plateau of constant thickness. This means that either more of the amorphous phase around the crystalline regions is removed or that the crystalline growth is enhanced.

For even longer $t_{\mathrm{H}}$ the resulting thickness drops to zero. This abrupt transition to "no growth" does not correspond to an etch rate. The deposited amorphous films are completely etched away in each individual sequence, i.e., after the first sequence of deposition and hydrogen treatment a bare substrate is left for the second deposition which is again completely etched away, etc. Thus ideally one would expect a step function above some critical time $t_{C 2}$. The finite slope is due simply to the experimental uncertainties concerning, e.g., the thickness measurements.

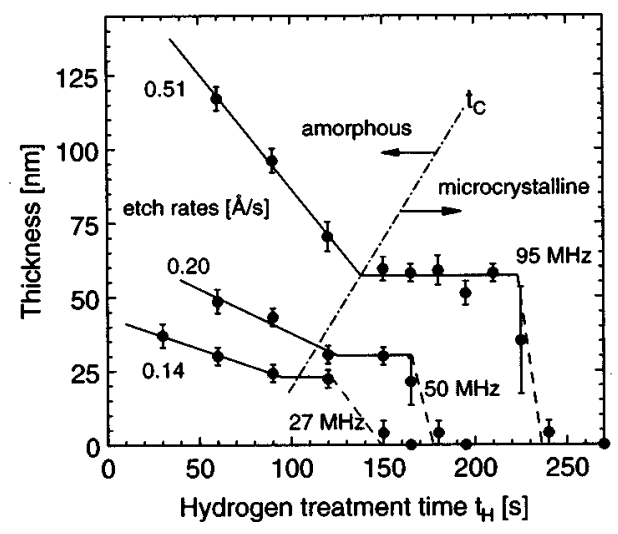

FIG. 1. Thickness of the layer-by-layer samples with 15 cycles and constant deposition time $t_{\mathrm{dep}}=12 \mathrm{~s}\left(t_{\mathrm{H}}\right.$ series). The three curves correspond to the three different plasma excitation frequencies. The etch rates indicated were computed from the linear decrease of thickness for $t_{\mathrm{H}}<t_{C}$. The lines are guides to the eyes.

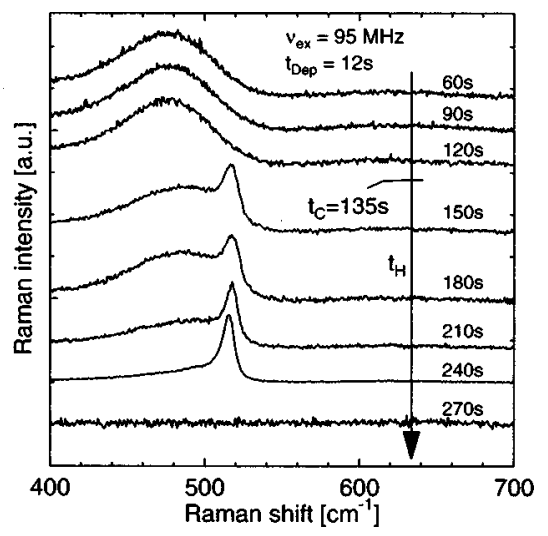

FIG. 2. Raman spectra of the samples prepared at $95 \mathrm{MHz}\left(t_{\mathrm{H}}\right.$ series $)$. The crystalline phase is only observed for hydrogen treatment times $t_{\mathrm{H}}$ longer than $t_{C}$.

The reduction of film thickness to a certain value in each layer-by-layer cycle might be crucial in the process of microcrystalline growth. In this case a variation of the initially deposited layer thickness with constant $t_{\mathrm{H}}$ would show similar critical thickness. The results of such an experiment are shown in Fig. 3.

The substrate temperature was lower in this series, causing a shift in the time values by rate effects. Nevertheless, the shape of the curve shows the behavior expected i.e., for deposition times $t_{\text {dep }}$ longer than $30 \mathrm{~s}$ the thickness increases linearly while the structure of the films is amorphous. The slope of this linear increase is in good agreement with the deposition rate of $2.5 \AA / \mathrm{s}$ for $a$ - $\mathrm{Si}: \mathrm{H}$ measured in a separate experiment. Only by reducing $t_{\text {dep }}$ to less than $30 \mathrm{~s}$ could microcrystalline growth be achieved. Also, a plateau of constant thickness is observed.

The critical thickness for microcrystalline silicon film formation in each LbL cycle seems to increase with the plasma excitation frequency (see Fig. 1). A plateau of constant thickness was observed at a net growth rate of $15 \AA$ cycle for $\nu_{\mathrm{ex}}=27 \mathrm{MHz}, 20 \AA /$ cycle for $\nu_{\mathrm{ex}}=50 \mathrm{MHz}$, and 38 $\AA$ /cycle for $\nu_{\text {ex }}=95 \mathrm{MHz}$. Whether this can be interpreted as an increase of the "interaction depth" with increasing $\nu_{\mathrm{ex}}$ cannot be determined at present.

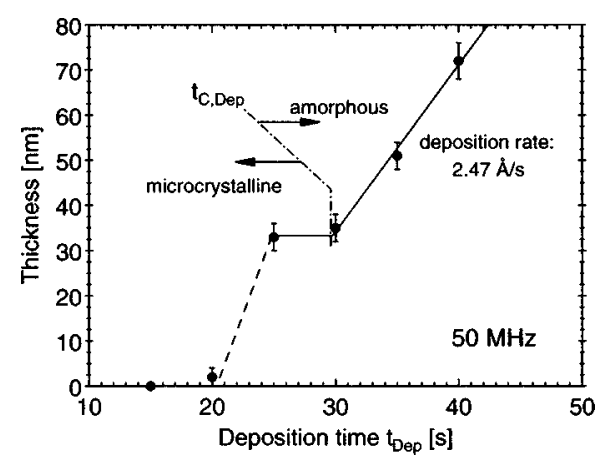

FIG. 3. Thickness of layer-by-layer films prepared with 15 cycles at constant hydrogen treatment time $t_{\mathrm{H}}=150 \mathrm{~s}\left(t_{\mathrm{dep}}\right.$ series $)$. The plasma excitation frequency was $50 \mathrm{MHz}$. The deposition rate was computed from the slope of the increase of film thickness for $t_{\mathrm{dep}}>t_{C \text {, dep }}$ and equals the deposition rate for the continuous deposition of $a-\mathrm{Si}: \mathrm{H}$. 


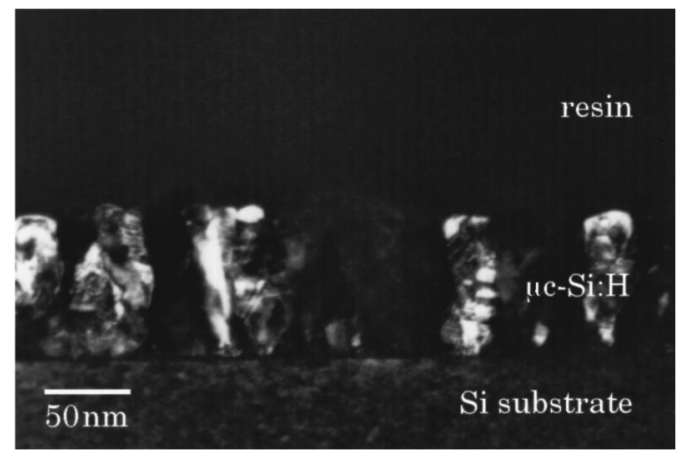

FIG. 4. Transmission electron microscopy micrograph of a layer-by-layer film deposited at $50 \mathrm{MHz}$ with 50 layer-by-layer cycles and $t_{\text {dep }} / t_{\mathrm{H}}$ $=12 \mathrm{~s} / 150 \mathrm{~s}$ (see Ref. 11). The cyclic nature of the layer-by-layer process cannot be observed.

The thickness of microcrystalline silicon grown per LbL cycle is only a few nm. Thus a distinction between the "surface" or "bulk" process is difficult. We suppose that in each cycle the material deposited has to be etched down close to the layer which was developed during preceding process steps. If this layer includes crystallites, preferential etching will mainly remove the amorphous phase. ${ }^{4,5}$ In the next deposition step the crystalline structure is preserved for a few monolayers, which means the crystallite columns grow. Once the crystallites are exposed at the surface, other processes like enhanced mobility of film precursors due to hydrogen coverage $e^{6,7}$ and chemical transport within the deposition chamber ${ }^{8}$ further promote crystallite formation.

If subsurface reactions are responsible for a phase transformation process, ${ }^{2,3}$ our results indicate that the interaction depth of this mechanism is limited to a few $\mathrm{nm}$. Otherwise it cannot be understood why a significant amount of the crystalline volume fraction is only observed when the hydrogen treatment time $t_{\mathrm{H}}$ exceeds a sharp value $t_{C}$ and the etch rate changes drastically at this point. Further, a phase transformation in the film's near surface region would imply that, for $t_{\mathrm{H}}<t_{C}$, films are grown that have alternating crystalline and amorphous layers. In contrast to this picture the structure of our microcrystalline films is not layer like but instead exhibits columnar grains which reach from the substrate to the surface (Fig. 4), a structure well known for $\mu c$-Si:H prepared with continuous growth methods. ${ }^{9,12}$
In summary, application of very high plasma excitation frequencies (27-95 MHz) in the LbL process gave the following results.

(1) In the LbL process the thickness of each layer grown under $a$-Si:H growth conditions must not exceed or must be reduced to a few $\mathrm{nm}$ by hydrogen treatment until microcrystalline formation is obtained.

(2) Continuous hydrogen treatment of pure bulk $a-\mathrm{Si}: \mathrm{H}$ results in net etching. No formation of the crystalline phase due to subsurface reactions or chemical transport is observed.

(3) Subsurface reactions caused by hydrogen treatment seem to be limited in their interaction depth to a few $\mathrm{nm}$ and can explain our results if one assumes the presence of a substrate (e.g., already grown crystallites) within this few nm necessary for phase transformation.

(4) The films deposited in our study exhibit columnar crystallites extending from the substrate to the surface and not a layer like structure corresponding to the cyclic nature of the LbL process.

The authors thank A. Lambertz and D. Steinbacher for technical assistance. This work was supported by the Bundesministerium für Bildung und Forschung (BMBF).

${ }^{1}$ A. Asano, Appl. Phys. Lett. 56, 533 (1990).

${ }^{2}$ K. Nakamura, K. Yoshino, S. Takeoka, and I. Shimizu, Jpn. J. Appl. Phys., Part 1 34, 442 (1995).

${ }^{3}$ H. Shirai, J. Hanna, and I. Shimizu, Jpn. J. Appl. Phys., Part 2 30, L679 (1991).

${ }^{4}$ I. Solomon, B. Drevillon, H. Shirai, and N. Layadi, J. Non-Cryst. Solids 164-166, 989 (1993).

${ }^{5}$ C. C. Tsai, G. B. Anderson, R. Thompson, and B. Wacker, J. Non-Cryst. Solids 114, 151 (1989).

${ }^{6}$ A. Matsuda, J. Non-Cryst. Solids 59\&60, 767 (1983).

${ }^{7}$ K. Nomoto, Y. Urano, J. L. Guizot, G. Ganguly, and A. Matsuda, Jpn. J. Appl. Phys., Part 2 29, L1372 (1990).

${ }^{8}$ K. Saitoh, M. Kondo, M. Fukawa, T. Nishimiya, A. Matsuda, W. Futako, and I. Shimizu, Appl. Phys. Lett. 71, 3403 (1997).

${ }^{9}$ M. Luysberg, P. Hapke, F. Finger, and R. Carius, Philos. Mag. A 75, 31 (1997).

${ }^{10}$ M. Heintze, W. Westlake, and P. V. Santos, J. Non-Cryst. Solids 164166, 985 (1993).

${ }^{11}$ L. Houben, M. Luysberg, P. Hapke, O. Vetterl, F. Finger, R. Carius, and H. Wagner, J. Non-Cryst. Solids 227-230, 896 (1998).

${ }^{12}$ C. C. Tsai, in Amorphous Silicon and Related Materials, edited by $\mathrm{H}$. Fritzsche (World Scientific, Singapore, 1988), p. 123. 